\title{
G20 and Global Risk Analysis ${ }^{1}$
}

\author{
E. Gurvich, I. Prilepskiy
}

Evsey Gurvich - Candidate of Science (Physics and Mathematics), Head, Economic Expert Group; Head, Centre for Budget Analysis and Forecasting, Financial Research Institute; bldg. 2, 3 Nastasiynsky Pereulok, 127006, Moscow, Russian Federation; E-mail: egurvich@eeg.ru

Ilya Prilepskiy - Candidate of Science (Physics and Mathematics), Head of Global Economy Division, Economic Expert Group; Senior Researcher, Centre for Budget Analysis and Forecasting, Financial Research Institute; bldg. 2, 3 Nastasiynsky Pereulok, 127006, Moscow, Russian Federation; E-mail: iprilepskiy@eeg.ru

\begin{abstract}
This article studies the work carried out by the Group of 20 (G20) between the global crises of $2008-09$ and 2020. Active 620 efforts to ensure financial stability and control imbalances helped to mitigate vulnerabilities to crises of the 2008-09 type. Other key achievements included the transition of several G20 members to market-determined exchange rates and the Standard for Automatic Exchange of Financial Account Information as a part of the effort to combat base erosion and profit shifting. However, the G20 proved unprepared for the 2020 crisis, even though G20 leaders had noted the risks linked to infectious diseases in 2015. During the period between the crises, the G20 failed to establish an effective system for analyzing global risks. Indeed, its analysis was mainly adaptive as opposed to forward-looking; no mechanism was formed for controlling policies to manage risks. G20 members' involvement in the analysis was inadequate, reflecting the consistent pattern of lower incentives for cooperation in the context of comparatively benign global economic conjunctures. Currently, however, the importance of managing global systemic risks is obvious and is reflected in the G20 Action Plan for supporting the global economy through the COVID-19 pandemic.

This article presents recommendations for the key elements of this risk management (systematic identification of most probable/destructive vulnerabilities; development of strategies to minimize critical risks and mitigate their possible consequences; monitoring for early warning signs of the most critical vulnerabilities; organizing prompt consultations and adopting swift measures in response to the materialization of globally important risks), including mechanisms for members' self-accountability and collaboration with international organizations. Management of systemic risks should start with resolving the challenges related to the COVID-19 pandemic: improving public health response systems; promoting structural economic transformations while ensuring prompt return to full employment; and striking the right balance between economic stimulus and macroeconomic stability.
\end{abstract}

Key words: G20; global governance; international organizations; global risks; economic policies coordination; anti-crisis measures

For citation: Gurvich E., Prilepskiy I. (2021). G20 and Global Risk Analysis. International Organisations Research Journal, vol. 16, no 2, pp. 55-69 (in English). DOI: 10.17323/1996-7845-2021-02-04

\section{Introduction}

The crisis caused by the COVID-19 pandemic has much in common with the 'Great Recession' of 2008-09. First, since the end of the Second World War, only those two crises resulted in fall in the global output; second, in both cases, crises engulfed almost all the countries; third,

${ }^{1}$ The editorial board received the article in February 2021. 
both crises emerged suddenly, thus necessitating the adoption of mitigating measures offhand. For instance, in April 2008 the IMF predicted global growth in 2009 at 3.8\%, while actually global output contracted by $0.1 \%$. During the 'coronacrisis,' the gap between expectations and reality was even wider. Indeed, in October 2019, the IMF anticipated global growth of $3.4 \%$ for 2020; the estimate for that year made in January 2021 amounted to $-3.5 \%$. In turn, the 2021 conjuncture is in many ways similar to 2010. Both then and now, rapid global recovery took place, spurred to a major extent by implementation of prompt coordinated efforts by key G20 economies.

Recall that the current stage in the evolution of G20 work commenced precisely during the 'Great Recession,' when the growing role of emerging economies made their participation in addressing the acute challenges to the global economy an objective necessity. Thus, the efforts of the G20, as a more representative forum compared to the G7, received a major boost and a higher political prominence. The 'coronacrisis' may therefore be considered as a milestone marking the end to the first round of G20 work and the start of the second round in similar circumstances. Note, however, that the preliminary results of that first round get very mixed assessments in the literature. Some experts regard G20 work to be quite successful [Larionova et al., 2019; Dupuis, Nahoum, 2017], while others contend that this work turns less and less prominent and effective as the time passes [Triggs, 2018; Bery, Biondi, Brekelmans, 2019]. The aim of the current study is to assess the effectiveness of G20 work in controlling global economic risks and to develop corresponding recommendations. This element of the G20 agenda is highly relevant. Indeed, in the aftermath of crises (both the 'Great Recession' and the 'coronacrisis'), G20 priorities, on top of supporting the economy and returning to the sustainable mediumterm growth path, inevitably include mitigating vulnerabilities to tail risks that were the primary causes of crises. In 2021, this means the focus on 'Health as a Global Common' in response to pandemic risks; in 2010, this meant the focus on the reforms of the global financial system in response to its fundamental vulnerabilities pre-2007 [G20, 2010b; 2021].

First, we consider G20 response to the risks resulting in the 'Great Recession,' as well as the place of risk analysis on the G20 agenda between the crises. Second, we study the advantages and drawbacks of the current G20 system for risk analysis in more detail and develop recommendations for modifying it. Finally, we juxtapose vulnerabilities which are most relevant as of 2021 with the current G20 priorities.

\section{G20 Work in the Aftermath of the 'Great Recession'}

There is a broad consensus on the positive impact of G20 efforts at the initial stage - during the 'Great Recession' and immediately afterwards. During that phase, newly expanded G20 work was aimed at minimizing the consequences of crisis shocks (i.e. the risks that materialized) and preventing the same shocks from repeating in the future. Since direct and indirect causes of the 2008-09 crisis included primarily the build-up of risks within the financial system and the expansion of global current account imbalances, it is not surprising that precisely these problems took a central place on the G20 leaders' agenda in 2009 and first post-crisis years. Indeed, analysis of key G20 Summit documents (leaders' statements and declarations, action plans) demonstrates that up to and including 2011, these areas accounted for more than $50 \%$ of 'risks' and 'challenges' mentioned therein. During that period, the G20 managed to approve large-scale measures for providing liquidity to key economies, implementing substantial fiscal stimulus packages, strengthening international coordination of anti-crisis policies. As an example, IMF resources were considerably expanded, enabling the Fund to provide additional credits to the tune of $\$ 250$ billion, thus considerably mitigating the emerging liquidity deficits. 
Another key G20 work area was a comprehensive endeavour to enhance financial stability in order to prevent future crises similar to the 'Great Recession.' Thanks to concerted efforts of the G20, FSB, BCBS, new macroprudential regulatory standards aimed at ensuring global financial stability were adopted by most key economies.

In the end, the joint efforts of G20 economies resulted in important progress in ensuring financial stability and controlling imbalances. As concerns the policies, successes included promotion of global financial reforms with a particular focus on macroprudential measures; establishment of the FSB as an important institution operating on a permanent basis; adoption of indicators for mitigating global imbalances by G20 leaders. As concerns the results, the global financial system successfully overcame the shocks in 2013 and 2018 linked to tighter US monetary policies, as well as the extremely strong liquidity shock in March 2020 due to the rapid proliferation of COVID-19 pandemic. Global current account imbalances, in turn, have remained 1.5-2 times lower than their pre-crisis values since 2009 [IMF, 2020].

On the whole, it may be stated that the G20 has largely succeeded in preventing the recurrence of the 'Great Recession,' having eliminated the preconditions of such crises. Besides the initial 'crisis-related momentum,' this required the constant adaptation to evolving financial stability risks; analysis of G20 Summit documents reveals that up to 2019, such risks accounted for more than $1 / 3$ of all 'risks' and 'challenges' mentioned therein. This is likely both due to foreseeable 'migration' of risks from banks to non-bank financial organizations (as the regulation of the former grew more stringent) and due to technological progress (which e.g. led to establishment of markets for crypto-assets). On the other hand, it is clear that, while huge and important G20 efforts succeeded in resolving the problems of 'the previous crisis,' they failed to prevent the new and even more destructive crisis of a different nature.

Soon after the 'Great Recession' was over, the 'basis' of long-term work areas on the G20 agenda started to expand through the new items suggested by Presidencies of the time. Some of these new items stayed on the G20 agenda afterwards, while others were soon superseded by new topics. On the whole, the G20 agenda was continuously expanding, both in term of the range of topics and the nature of problems being discussed. At first, this process was defined by the challenges emerging in due course in the aftermath of the crisis, such as accelerating recovery, reducing excessive fiscal deficits and public debt resulting from the ambitious stimulus measures etc. At this stage, for instance, the G20 adopted the Framework agreement for strong, sustainable and balanced growth aimed at creating the most favourable conditions for economic recovery in all G20 members; promoted agreements on international trade facilitation; endorsed measures for spurring investment in infrastructure. Concerning the latter, for example, the G20 launched the Global Infrastructure Initiative and adopted the Roadmap to Infrastructure as an Asset Class. As the years passed, the G20 agenda diversified further and further and came to include, among others, energy efficiency and promoting renewables; supporting digitalization; employment challenges and the fight against poverty; climate; food security; migration etc. On the whole, the G20 has gradually turned from countering global risks to supporting global economy and development.

One of the lines of criticism of G20 work [Triggs, 2018] is that many commitments adopted by the G20 after the crisis were implemented only to a limited extent (e.g. as concerns fiscal consolidation programs). Similarly, [Bery, Biondi, Brekelmans, 2019] note that once the acute phase of the crisis was over, the willingness of G20 economies (especially advanced ones) for cooperation fell dramatically, and they turned to implementing fiscal and monetary policies based mainly on their narrow interests. On the other hand, [Larionova et al., 2019] regard G20 efforts as active and fruitful. They stress that during the first decade of these efforts, G20 members have adopted 2330 commitments and achieved substantial progress in their implementation. Likewise, [Dupuis, Nahoum, 2017] provide evidence of active and productive G20 work. 
We feel that both viewpoints are partially valid. On the one hand, after the 'Great Recession' the G20 has prepared and implemented a number of major initiatives. The following achievements deserve particular credit. First, more and more G20 members have turned to market-based exchange rates and rejected devaluation as a tool for increasing external competitiveness. Second, the G20 endorsed automatic exchange of tax information in the context of efforts to combat base erosion and profit shifting.

On the other hand, the number of concrete actions and results achieved by the G20 has indeed declined gradually. In our view, this is a natural consequence of agenda-setting mechanisms employed by the G20. During the first post-crisis years, actions focused heavily on resolving acute problems common for all countries, i.e. mitigating the crisis impacts; achieving fast recovery; returning to sustainable levels of fiscal deficits and public debt; developing measures to prevent the emergence of new financial imbalances. Solving these problems required a high degree of cooperation; however, G20 members had a clear understanding of serious consequences if they had failed to agree on a common work program. Thus, the context of a severe crisis impelled the G20 to achieve consensus on most agenda items, which, in turn, ensured the success of coordinated actions that followed.

The agenda-setting mechanism utilized in the aftermath of the crisis has important benefits. First, it ensured the wide range of agenda items; second, it allowed the Presidencies to initiate joint discussions of problems considered by them as priorities. However, on the other hand, such a decentralized mechanism resulted in proliferation of agenda topics regarding which G20 members had widely varying assessments as concerns their importance at global and national levels, as well as potential solutions. As a result, the opportunities for adopting, and particularly implementing, common action plans were narrowed. For instance, the importance of the problem of job creation notwithstanding, the progress of each country in this area is almost completely dependent on its own efforts only. Conversely, the problem of reducing greenhouse gas emissions requires close coordination, but G20 members differ widely as regards the preparedness to limit such emissions if introducing limits has negative impact on output dynamics. The overarching conclusion is that the G20 agenda-setting mechanism succeeded in widening the range of topics considered, but the price for that was a lower effectiveness of G20 actions. This reflects the standard pattern: while acute global problems inevitably result in 'aggregating forces' forcing the countries to cooperate in addressing global challenges, in the aftermath of the crises, 'centrifugal forces' grow and individual interests come to dominate common ones.

\section{G20 Analysis of Global Risks}

It seems that the key piece of evidence for the need of substantial reforms in G20 work is not the overall reduction in its effectiveness, but, rather, the failure to timely identify the spread of virulent infectious diseases as one of the main threats to the global economy. Hence, the G20 made no serious contribution to preventing the materialization of the strongest global risk of all the years of its existence, that is, the COVID-19 pandemic (note, however, that this refers likewise to most other international organizations, including the WHO). It should be stressed that the G20 did consider the problems related to spread of dangerous infectious diseases, starting in 2015, but they remained relegated to the fringes of actual G20 work. For instance, during the Ebola epidemic in West Africa, in Antalya G20 leaders agreed that "...attention should be given to global health risks, such as ... infectious disease threats and weak health systems...these can significantly impact growth and stability" [G20, 2015]. However, necessary measures were not taken, resulting, for instance, in PPE shortages and overload of health systems during the COVID-19 pandemic. 
Weakness of measures to address the threats of infectious diseases is in marked contrast to clear signals regarding the serious risks related to such diseases. In particular, the report on [Global Health Security Index, 2019] stressed forcefully the extremely low capacity of most countries to prevent, detect and address critical risks to public health. None of the 195 countries considered demonstrated full preparedness to epidemics/ pandemics, while only around $10 \%$ of countries were assessed as ready to promptly deploy the necessary medical measures in case extreme threats to public health emerged.

In our view, the fact that the G20 overlooked the pandemic threats reflected the overarching weakness of its system for global risk analysis, which was repeatedly subject to justifiable criticism. Improving this system was one of the key recommendations made by the G20 Eminent Persons Group on Global Financial Governance [EPG, 2018] in response to the assignment made by G20 finance ministers and central bank governors [G20, 2017b]. Focusing on financial risks, the experts developed the following proposals:

- integrate the surveillance efforts of the IMF, FSB and BIS in a coherent global risk map to minimize surveillance gaps;

- incorporate non-official and contrarian views systematically;

- build on the existing IMF-FSB Early Warning Exercise (which is aimed at analyzing the consequences of tail risks' materialization and making the recommendations to mitigate them) to ensure policy follow-up from the global risk map.

Further study of documents endorsed by G20 leaders and G20 finance track ${ }^{2}$ reveals problems of risk analysis due to 1) its 'adaptive' rather than 'forward-looking' nature; 2) dependence on input from international organizations, especially the IMF. Indeed, as the Table 1 demonstrates, many risks were only discussed by the G20 after they had already materialized, even if this materialization was readily foreseeable (e.g. stronger negative effects of high public debt load in the euro area due to the feedback loops between government bond yields and banking system balances). The same refers to the problem of protectionism, given that G20 members had systematically violated the standstill agreement of the 2008 Washington Summit against new restrictions on global trade and investment [G20, 2008] well before the Trump administration came to power in the US [OECD, WTO, UNCTAD, 2016].

Dependence on the IMF analysis is highlighted by the fact that in describing most risks, G20 documents tracked closely the Fund's G20 Surveillance Notes (see Table 1). On the whole, comparison of $\mathrm{G} 20$ documents to reports prepared for summits and ministerial meetings demonstrates that, while the FSB is the main forum for assessing global financial stability risks for the G20, the IMF plays the similar role as far as risks to macroeconomic stability and growth are concerned. Regarding certain elements of the macroeconomic agenda (such as risks of slower productivity growth, impacts of ageing societies, protectionism, negative impact of inequality on growth), the OECD, WB, WTO, ILO also make significant contributions.

At the same time, it should be stressed that in many instances when the G20 did focus on key 'forward-looking' risks, this was due to corresponding agenda items being selected as priorities by the Presidencies themselves. Examples include discussions of inequality and social discontent during the Russian Presidency in 2013; of employment risks related to digitalization during the Argentine Presidency in 2018; of macroeconomic impacts of ageing during the Japanese Presidency in 2019.

${ }^{2}$ Discussions of macroeconomic and financial agenda by G20 finance ministers and central bank governors prepared by their deputies with input from G20 working groups (Framework Group, Investment and Infrastructure Group, International Financial Architecture Group). 
Table 1. Global economic risks noted in the final documents of G20 Summits and Finance Ministers'/ Central Bank Governors' meetings

\begin{tabular}{|c|c|c|c|c|c|}
\hline Risk & $\begin{array}{l}\text { Years of con- } \\
\text { sideration }\end{array}$ & Risk & $\begin{array}{l}\text { Years of con- } \\
\text { sideration }\end{array}$ & Risk & $\begin{array}{l}\text { Years of consid- } \\
\text { eration }\end{array}$ \\
\hline \multicolumn{6}{|c|}{ Risks for macroeconomic stability } \\
\hline High public debt & $\begin{array}{l}\text { 2010, 2011, } \\
\text { 2012, 2013* } \\
2015\end{array}$ & $\begin{array}{l}\text { 'Sudden stop' } \\
\text { and volatility of } \\
\text { capital flows }\end{array}$ & $\begin{array}{l}2010,2011, \\
2013,2015, \\
2016,2017, \\
2018,2019, \\
2020\end{array}$ & $\begin{array}{l}\text { High com- } \\
\text { modity prices }\end{array}$ & $2011,2012 *$ \\
\hline $\begin{array}{l}\text { Public debt - } \\
\text { bank balances } \\
\text { feedback loop }\end{array}$ & $\begin{array}{l}2011,2012 \\
2013\end{array}$ & \begin{tabular}{|l|}
$\begin{array}{l}\text { Overheating of } \\
\text { emerging markets }\end{array}$ \\
\end{tabular} & 2011,2013 & $\begin{array}{l}\text { Economic } \\
\text { uncertainty }\end{array}$ & $\begin{array}{l}2012,2013, \\
2020\end{array}$ \\
\hline $\begin{array}{l}\text { Financial market } \\
\text { volatility }\end{array}$ & $\begin{array}{l}2014,2016, \\
2018\end{array}$ & \begin{tabular}{|l|} 
Too low inflation \\
and its impact on \\
public debt
\end{tabular} & 2015,2016 & Low oil prices & 2016 \\
\hline $\begin{array}{l}\text { Brexit without free } \\
\text { trade agreement }\end{array}$ & 2016 & $\begin{array}{l}\text { Insufficient policy } \\
\text { buffers }\end{array}$ & 2018 & & \\
\hline \multicolumn{6}{|c|}{ Risks for short-term growth } \\
\hline Low demand & $\begin{array}{l}\text { 2009, 2013, } \\
2015^{*}\end{array}$ & \begin{tabular}{|l|} 
Premature with- \\
drawal of stimulus \\
measures
\end{tabular} & 2009,2020 & $\begin{array}{l}\text { Excessive fiscal } \\
\text { consolidation } \\
\text { in the US }\end{array}$ & 2012 \\
\hline \multicolumn{6}{|c|}{ Medium- and long-term risks for growth and employment } \\
\hline Protectionism & \begin{tabular}{|l} 
2012, 2013, \\
2016, 2018, $^{2019^{*}, \mathbf{2 0 2 0}}$ *
\end{tabular} & \begin{tabular}{|l|} 
Low potential \\
growth, hysteresis \\
effects
\end{tabular} & $\begin{array}{l}\text { 2012*, 2015*, }^{*} \text { 2016*, 2018*, } \\
\text { 2020* }^{*}\end{array}$ & $\begin{array}{l}\text { Inequality and } \\
\text { social discon- } \\
\text { tent }\end{array}$ & $\begin{array}{l}\text { 2013*, 2015*, } \\
\text { 2016, 2018*, } \\
\text { 2020* }\end{array}$ \\
\hline $\begin{array}{l}\text { Job losses due to } \\
\text { digitalization }\end{array}$ & 2018*, 2020* & \begin{tabular}{|l|}
$\begin{array}{l}\text { Impacts of ageing } \\
\text { societies }\end{array}$ \\
\end{tabular} & 2019* & & \\
\hline \multicolumn{6}{|c|}{ Risks due to non-economic causes } \\
\hline Geopolitical risks & $\begin{array}{l}2012,2014, \\
2015,2016, \\
2018,2019, \\
2020\end{array}$ & $\begin{array}{l}\text { Infectious dis- } \\
\text { eases }\end{array}$ & $\begin{array}{l}2015, \mathbf{2 0 1 6}, \\
\mathbf{2 0 2 0}\end{array}$ & $\begin{array}{l}\text { Natural disas- } \\
\text { ters }\end{array}$ & $2019 *, 2020$ \\
\hline Climate change & $2020^{*}$ & & & & \\
\hline
\end{tabular}

Note. For risks which were earlier identified in the IMF Surveillance Notes, years of consideration are highlighted in bold; for those selected by Presidencies as priorities - by an '*' symbol.

Source: authors' analysis.

Overall, the analysis of prior G20 work points at the need to re-focus its activities on controlling global systemic risks as a key common goal. Such control entails:

1) Systematic identification of most probable/ potentially most destructive threats;

2) Agreeing on action plans for minimizing these critical risks and mitigating their impacts in case they materialize;

3) Monitoring the early warning signs of most critical threats;

4) Organizing prompt meetings and adopting prompt measures in case globally important risks materialize in a significant way. 
Adopting global risk control as a priority would mean re-orienting G20 work from passive reaction to materialization of threats to 'forward-looking' policies based on early identification of problems that may emerge in the future. This would increase the odds of preventing new global shocks, thus resulting in significant advantages for the G20 and the world at large. It suffices to mention that, by spring 2021, the number of confirmed COVID-19 cases has exceeded 125 million, while global output losses in 2020 caused by the pandemic are assessed at more than $\$ 4.6$ trillion.

How exactly could the process of global risk identification look like? It would probably require an increase in members' input in line with the 'member-owned, member-led' principle applied earlier during the monitoring of implementation of G20 growth strategies [G20, 2017a]. For instance, the process could be structured as follows:

1) Identifying the range of key risks through the input of G20 members, international organizations (including not only the IMF, FSB, BIS, OECD, WB, WTO, ILO, but also e.g. the WHO, UNCTAD) and external experts. Importantly, the definition of risks should be sufficiently wide (e.g. not only addressing the risks linked to COVID-19 pandemic, but also controlling global threats linked to the whole spectrum of dangerous infectious diseases). The initial list of risks for consideration should also be as wide as possible. For example, it could include irregular threats that cannot be predicted to any reasonable degree of precision (so-called 'grey swans'), such as global disruption of energy infrastructure and telecommunications due to anomalous solar flares ${ }^{3}$.

2) Filling out questionnaires to obtain members' assessment of a) the risk horizon; b) the probability of risk materialization; c) possible impacts; d) measures taken to prevent materialization/ measures that countries are ready to take if the risk materializes.

3) Scenario analysis of risks' materialization and country responses by the IMF, FSB, BIS based on data from 2), with an emphasis on comparing the dynamics of key macroeconomic variables (such as GDP, public debt, employment) with the scenarios of implementing international organizations' own recommendations; discussion of results at the meetings of G20 finance ministers and central bank governors.

4) Developing the programs for mitigating threats and their impacts based on the results of scenario analysis; adopting commitments for implementation of such programs.

5) Developing the indicator systems for monitoring threats where appropriate.

6) Sharing country data on (self-assessed) progress in implementing risk-mitigating measures and possible modifications of response strategies based on results of scenario analysis (e.g. due to possible spillover effects). This point is crucial, since, as demonstrated in [Larionova, Rakhmangulov, Shelepov, 2016], the presence of self-accountability mechanisms results in a significant increase in effectiveness of G20 efforts.

Setting these targets will help to focus G20 efforts on resolving not only current, but also future challenges. Another advantage of such an approach is that it combines existing G20 assignments (e.g. as regards scenario analysis; [G20, 2020]) with the EPG recommendations, as well as with the short-lived experience of working with country-led risk assessments. Indeed, in 2018, during the Argentine Presidency, G20 Framework Working Group gathered and analyzed such assessments; however, the focus on only three (already materializing) risks identified by the IMF (retreat from cross-border integration, tighter global financial conditions, structurally weak growth), along with the absence of scenario analysis follow-up and the lack of high-level discussions, resulted in the failure of those efforts.

${ }^{3}$ See: https://www.dbresearch.com/servlet/reweb2.ReWEB?rwsite=RPS_EN-PROD\&rwobj= ReDisplay.Start.class\&document=PROD0000000000509478 


\section{Global Risks in 2021 and G20 Actions}

A good example of assessing systemic risks is provided in annual reports by the World Economic Forum (WEF). In the latest issue published in January [2021], risks are subdivided into three categories: 'clear and present dangers' (short-term risks with a horizon of 0-2 years); 'knock-on effects' (medium-term threats, 3-5 years); 'existential threats' (long-term, 5-10 years). When analyzing the risk matrix according to likelihood and impact of risks, two top risks emerge as being both highly probable and destructive: spread of infectious diseases (existing and/ or new ones) and the failure of efforts to combat climate change. Both are also assessed by key risks by the G20 finance track [G20, 2021]. Obviously, in the short-term, the first threat deserves most attention; in our view, several recommendations from The Global Health Security Index report remain highly relevant in this respect, for instance,

1)Establishing new financing mechanisms to strengthen preparedness to dangerous infectious diseases at global and national levels;

2) Agreeing on the standards for prompt data reporting and data sharing for cases of serious contagious diseases;

3) Developing requirements for national programs aimed at combating the spread of dangerous infectious diseases;

4) Developing the protocols to regularly assess robustness of national systems for epidemiological security and to publish the results of such assessments.

These tasks could be complemented by efforts in adjacent areas, e.g. assessing the possibility and need for establishing a dedicated international centre responsible for monitoring the cross-border spread of serious contagious diseases, or analyzing the approaches to helping the least developed countries combat the COVID-19 pandemic.

Another important area for G20 deliberations is related to economic impacts of the pandemic. The agenda for 2021 includes discussing the challenge of promoting strong recovery, but it should be noted that this problem is a multidimensional one.

Output fall in 2020 was of completely different nature as compared to prior crises; therefore, recovery demands different policies as well. As noted by several authors [Barrero, Bloom, Davis, 2020], the current crisis is accompanied by structural shifts in production which will have long-term consequences. While, in the past, output fall and recovery were not associated with major structural shifts, at the current juncture it is obvious that many sectors will not return to pre-crisis levels of activity in the foreseeable future. Those include, above all, tourism, hospitality, catering, transport. Therefore, the task of supporting a partial reallocation of resources to other sectors comes to the forefront. Update of the G20 Action Plan for supporting the global economy through the COVID-19 pandemic contains a corresponding commitment [G20, 2021].

Furthermore, during the current crisis, labour-intensive sectors dominated by the SMEs with limited financial buffers were the most affected ones. As a result, unemployment rose dramatically. It should be noted that countries vary widely as concerns their labour markets' capacity to adapt to shocks; as an example, the whole decade after the 'Great Recession,' in 2019, the unemployment rate in Greece still stood at $17 \%$. Thus, restoring full employment should be one of the priorities of anti-crisis policies in the coming years. Detailed studies of labour markets of those countries (including Russia) where unemployment reacts only weakly to negative shocks and rapidly returns to its natural level in the context of G20 commitment for analyzing best policy practices of labour market reforms [G20, 2021] would be valuable in this regard.

Another major point relates to fiscal policies. Many countries intend to continue with 2020 practice of generous fiscal stimulus, so as to support strong recovery. Note, nevertheless, 
that the need for fiscal consolidation was one of the major acute problems in the aftermath of the 'Great Recession.' Back then, the G20 agreed upon the gradual return to the safe levels of fiscal deficits and public debt at the Toronto and St Petersburg Summits [G20, 2010a; 2013]. However, the current levels of fiscal stimulus far exceed those during the 'Great Recession.' Indeed, in 2009, average G20 general government deficit amounted to $7.6 \%$ of GDP, while public debt grew by 6.8 percentage points, from 66.0 to $72.8 \%$ of GDP [IMF, 2012]. In 2020, by contrast, according to the preliminary IMF estimates, average G20 fiscal deficit stood at 13.0\% of GDP, while the public debt grew by 15.5 percentage points (from 91.3 to $106.8 \%$ of GDP); in particular, for G20 advanced economies, the increase in public debt amounted to almost 20 percentage points [IMF, 2021]. This entails the following challenges deserving G20 deliberations: 1) What is the right balance between supporting economies in the crisis aftermath and ensuring long-term macroeconomic stability? 2) What should the new targets for G20 fiscal variables look like once the output has recovered? 3) What should the timeframe for achieving those post-crisis targets be? All these are the challenges lacking easy responses and requiring coordinated actions. It may be recalled that some countries, such as Greece or Spain, faced extremely hard times in the 2010s after their fiscal deficits and public debts increased markedly. At the current juncture, the values of fiscal deficit and public debt are significantly higher for many countries; hence, the resulting problems may be even more enduring and difficult to solve. However, in contrast to 2010 , so far the G20 as a whole has not adopted commitments on medium-term strategies for public debt reduction, although several counties (Russia, UK) did announce necessary consolidation measures.

Apart from fiscal risks, other vulnerabilities that so far have not been adequately reflected in the G20 agenda include the threat of financial market disruption and a surge in capital flow volatility related to investors' concerns about the spike in inflation due to a marked shift to more accommodative monetary policies in virtually all G20 members in 2020 and to deployment of a new fiscal stimulus package in the US in 2021 in the context of an already speedy economic recovery. Moving away from the finance track agenda, heightened vulnerability of global economy to cyberattacks owing to a permanent shift to remote work after the COVID-19 pandemic should be highlighted.

\section{$* * *$}

G20 efforts after the 'Great Recession' contributed to a marked decline in global vulnerability to similar crises. However, the 'coronacrisis' has revealed insufficient effectiveness of G20's risk analysis system. As demonstrated in this paper, this is due to such features as its 'adaptive' rather than 'forward-looking' nature; focus on the IMF/ FSB recommendations rather than country views on risks; lack of systematic control of measures adopted in response to already identified risks. Taking into account these factors, along with the EPG recommendations, a framework for modifying G20 risk analysis is presented, emphasizing closer collaboration between G20 members and international organizations, as well as self-accountability mechanisms. So far, however, the study of the G20 2021 agenda reveals persistent focus on 'adaptive' risk response and comparatively little attention to 'forward-looking' fiscal and inflationary risks. The proposed extensions to the current G20 agenda and modifications of the framework for its future work could be expected to facilitate recovery of the global economy from the current crisis, mitigate the crisis consequences and enhance preparedness for future crises (fully preventing them whenever possible). 


\section{References}

Barrero J., Bloom N., Davis S. (2020). COVID-19 Is Also a Reallocation Shock. NBER Working Paper No 27137, National Bureau of Economic Research. Available at: https://doi.org/10.3386/w27137

Bery S., Biondi F., Brekelmans S. (2019). Twenty Years of the G20: Has It Changed Global Economic Governance? Russian Journal of Economics, vol. 5, no 4, pp. 412-40. Available at: https://doi.org/10.32609/j. ruje.5.49435

Dupuis F., Nahoum D. (2017). The G20's Accomplishments, 10 Years After the Crisis. Tresor-Economics, no 192. Available at: https://www.tresor.economie.gouv.fr/Articles/3fea63e5-d376-4770-882c-ee4bef9eab53/ files/6d802be5-07e6-4a8e-b305-95e303be9ce4 (accessed 15 May 2021).

Eminent Persons Group (EPG) (2018). Making the Global Financial System Work for All: Report of the G20 Eminent Persons Group on Global Financial Governance. Available at: https://www.globalfinancialgovernance.org/assets/pdf/G20EPG-Full\%20Report.pdf (accessed 4 December 2020).

Global Health Security Index (2019). Available at: https://www.ghsindex.org/ (accessed 15 May 2021).

Group of 20 (G20) (2008). Declaration of the Summit on Financial Markets and the World Economy. Washington DC, 15 November. Available at: http://www.g20.utoronto.ca/2008/2008declaration1115.html (accessed 4 December 2020).

Group of 20 (G20) (2010a). The G20 Toronto Summit Declaration. Toronto, 27 June. Available at: http:// www.g20.utoronto.ca/2010/to-communique.html (accessed 4 December 2020).

Group of 20 (G20) (2010b). Communique. Meeting of Finance Ministers and Central Bank Governors, Busan, 5 June. Available at: http://www.g20.utoronto.ca/2010/g20finance100605.html (accessed 24 March 2020).

Group of 20 (G20) (2013). G20 Leaders' Declaration. St Petersburg, 6 September. Available at: http://www. g20.utoronto.ca/2013/2013-0906-declaration.html (accessed 4 December 2020).

Group of 20 (G20) (2015). G20 Leaders' Communique. Antalya, 16 November. Available at: http://www.g20. utoronto.ca/2015/151116-communique.html (accessed 4 December 2020).

Group of 20 (G20) (2017a). G20 Hamburg Action Plan. Hamburg, 8 July. Available at: http://www.g20.utoronto.ca/2017/2017-g20-hamburg-action-plan.html (accessed 4 December 2020).

Group of 20 (G20) (2017b). Chair's Summary. G20 Finance and Central Bank Governors Meeting, Washington DC, 20-21 April. Available at: https://www.bundesfinanzministerium.de/Content/EN/Standardartikel/Topics/world/G7-G20/G20-Documents/Chairs-Summary-Washington-April-2017.pdf? blob $=$ publicationFile \&v $=3$ (accessed 4 December 2020).

Group of 20 (G20) (2020). Second G20 Action Plan Progress Report. Riyadh, 21-22. Available at: https://www. bundesfinanzministerium.de/Content/EN/Standardartikel/Topics/world/G7-G20/G20-Documents/202011-22-g20-riyadh-action-plan-progress-report.pdf?_blob=publicationFile\&v=2 (accessed 4 December 2020).

Group of 20 (G20) (2021). Communique. Second G20 Finance and Central Bank Governors Meeting, 8 April (Virtual). Available at: http://www.g20.utoronto.ca/2021/210407-finance.html (accessed 15 May 2021).

International Monetary Fund (IMF) (2012). Balancing Fiscal Policy Risks. Fiscal Monitor, April. Available at: https://www.imf.org/en/Publications/FM/Issues/2016/12/31/Balancing-Fiscal-Policy-Risks (accessed May 2021).

International Monetary Fund (IMF) (2020). World Economic Outlook, October 2020: A Long and Difficult Ascent. Available at: https://www.imf.org/en/Publications/WEO/Issues/2020/09/30/world-economic-outlook-october-2020 (accessed 4 December 2020).

International Monetary Fund (IMF) (2021). Government Support Is Vital as Countries Race to Vaccinate. Fiscal Monitor Update, January. Available at: https://www.imf.org/en/Publications/FM/Issues/2021/01/20/ fiscal-monitor-update-january-2021 (accessed 15 May 2021).

Larionova M., Ignatov A., Popova I. et al. (2019). G20 After 20 Years. Moscow: Publishing House Delo. (in Russian). 
Larionova M., Rakhmangulov M., Shelepov A. (2016). Explaining G20 and BRICS Compliance. International Organisations Research Journal, vol. 11, no 3, pp. 99-131 (in Russian and English). Available at: https://doi. org/10.17323/1996-7845-2016-03-99

Organisation for Economic Co-operation and Development (OECD), World Trade Organization (WTO), United Nations Conference on Trade and Development (UNCTAD) (2020). Reports on G20 Trade and Investment Measures (Mid-May to Mid-October 2016). Available at: https://www.oecd.org/daf/inv/ investmentpolicy/16th-Report-on-G20-Trade-and-Investment-Measures.pdf (accessed 4 December 2020).

Triggs A. (2018). Macroeconomic Policy Cooperation and the G20. The World Economy, vol. 41, no 5, pp. 1309-41. Available at: https://doi.org/10.1111/twec.12607

World Economic Forum (WEF) (2021). The Global Risks Report. Available at: https://www.weforum.org/ reports/the-global-risks-report-2021 (accessed 15 May 2021). 